\section{Body dissatisfaction among Iranian youth and adults}

\author{
Dismorfofobia entre jovens e adultos iranianos
}

Dismorfofobia entre jóvenes y adultos iraníes
Behshid Garrusi 1

Mohammad Reza Baneshi 2

doi: 10.1590/0102-311X00024516

\begin{abstract}
Despite the importance of body satisfaction on one's self image and well-being, little has been written about body image or how it affects people in Iran. The aim of this study is to assess body dissatisfaction and its risk factors in the general Iranian population. The sample size for this cross-sectional study included approximately 1,200 participants (both male and female) and was conducted in 2011. Body dissatisfaction (based on the Figure Rating Scale), demographic characteristics, socioeconomic status, body mass index (BMI) and use of the media were recorded. Nearly two thirds of the participants were included in the middle age group and roughly half of them had a university education. Approximately two thirds of the participants were satisfied with their body. The mean score of body dissatisfaction in women was greater than men $(p<0.0001)$. Age, gender, marital status and BMI had a significant relationship with body dissatisfaction. The finding of this study demonstrates that in Iran, body dissatisfaction and it consequences must be addressed. While the prevalence and pattern of body dissatisfaction in Iran is as high as other Asian countries, considering cultural variation within Asian countries is also important.
\end{abstract}

Body Image; Self Concept; Physical Appearance

\section{Correspondence}

B. Garrusi

Neuroscience Research Center, Institute of Neuropharmacology, Kerman University of Medical Sciences.

Kerman / Iran - 7616676166.

behshidgarrusi@gmail.com

1 Institute of Neuropharmacology, Kerman University of Medical Sciences, Kerman, Iran.

2 Institute for Futures Studies in Health, Kerman University of Medical Sciences, Kerman, Iran. 


\section{Introduction}

Body image is a term that refers to a person's inner understanding of his or her outward appearance (The Free Dictionary. http://medical-dictionary.thefreedictionary.com/body+image). It is a conceptual matter that includes a mental picture of a person's body. It encompasses two dimensions: perception of the appearance of one's body and emotional responses to this perception 1 .

Body image is a multidimensional concept that can be influenced by various factors. Some of these contributing factors include media, family, friends and cultural standards 2,3. Concern with one's appearance is not a consequence of modern culture but rather has existed throughout history. Historical data suggests that the concept of the ideal body has changed radically throughout the 20th century, especially for women. The slim body became an ideal for women during the 1960s 4, while a traditionally masculine body has been the ideal type for men 5 .

Studies have demonstrated that body dissatisfaction has increased 4,5. In recent years, however, the emphasis on fitness has become more prevalent among other societies as well as Western cultures $6,7,8,9,10$. Messages in Western media regarding attractive and ideal body types may be a cause of body dissatisfaction 11. Internalizing media messages can cause people to judge their body as unattractive. Individuals who compare themselves to attractive people represented in the media are prone to experience body dissatisfaction 12,13 , as well as discrepancies between perceived and ideal body image. Body dissatisfaction can induce severe health problems, such as eating disorders, or lead to the use of various invasive or non-invasive methods to achieve an ideal body. These methods include risky behaviours such as strenuous exercise, restricted diet, drug or substance abuse, and invasive surgery. Women more so than men, are engaging in unnecessary activities in order to change their bodies to that of the ideal type presented in the media $8,14,15$.

Similar to other Asian cultures, obesity in Iran during the past few decades has been considered a signifier of good health and wealth, while thinness is associated with illness and poverty 16 . However, in recent years, thinness has become important in Iran as it has in other Asian cultures. Body fitness is considered from two dimensions; health and attractiveness.

There is little research about Iranian body image, body satisfaction, and body change strategies. In Akiba's study, the comparison between body image for Iranian women (living in Iran) and American women showed that both had lower body satisfaction than men, but Iranian women had greater body satisfaction than American women 17. In another study, it was shown that body dissatisfaction and the desire to be thin were common in Iranian adolescent girls 18. Other similar studies emphasize the increase of body dissatisfaction and related issues such as weight management behaviours 19,20.

Although there are no official statistics about the frequency of cosmetic surgery or other body change strategies, the popularity of these activities appear to be increasing. Among these methods the incidence of cosmetic surgeries has increased, especially rhinoplasty.

The purpose of this study is to (a) assess overall body dissatisfaction and (b) identify factors that could affect body dissatisfaction in Iranians.

\section{Materials and methods}

This study was conducted in Kerman, the capital of the largest province in Iran. Adopting a multistage sampling scheme, 1,204 participants aged 15 to 55 years old were recruited.

In the developing of regression models, at least 10 events per independent variable (EPV) being tested are required. We selected a total of 1,204 subjects for this reason. First the city was divided in 10 blocks. From each block approximately 120 households were selected. The first household was selected randomly. The rest of the blocks were selected following a systematic sampling approach. If no one was at home, the next household was selected. In each household only one subject was interviewed. For the proportional distribution of males and females in the study, interviews were conducted in both mornings and afternoons.

This cross-sectional survey was conducted as part of the larger study Body Satisfaction and Related Issues in Iran. This study was approved by the Ethics Research Committee of vice chancellor for research in the Kerman Medical Sciences University (EC-KNRC/89-30). All participants signed the informed consent form. 


\section{Outcomes}

The main outcome of our study was the measuring of body dissatisfaction. For this purpose, we used the Figure Rating Scale 21,22. This scale includes nine silhouettes (male and female) that are numbered from 1 (very thin) to 9 (severely obese). Subjects were asked to identify the pictures that represent their current and ideal body, respectively. The absolute difference between current and ideal sizes was used as a measure of body dissatisfaction 20 . This simple body satisfaction assessment has been utilized by many studies with acceptable reliability and validity 22 . Although this scale was mostly used in studies with adolescents, some researchers used it for different gender and age groups 23,24,25,26. The psychometric properties of the Figure Rating Scale, written in Farsi, had an acceptable test-retest reliability $(\alpha=0.79)$, in addition to convergent validity and internal consistency 27 .

\section{Risk factors}

\section{- Demographic characteristics}

The demographic characteristics collected included gender, age $(<20,20-40,>40$ years old), and marital status (single, married, divorced, or widowed).

\section{- Socioeconomic status}

Socioeconomic status included level of education (illiterate, elementary school, high school, and university degree), occupation, and economic status (fair, medium, good, or excellent). The assessment of socioeconomic status was self-reported. Participants selected one of these classifications (fair, medium, good, or excellent) based on self-assessment.

\section{- Body mass index}

Additionally, a trained professional measured weight and height using standardized methods 28,29. Body mass index (BMI) was calculated according to the ratio of body weight $(\mathrm{kg})$ to the square of height $\left(\mathrm{m}^{2}\right)$. Finally, subjects were categorized into four groups: $<18.5$ (underweight), 18.5-24.9 (normal), 25-29.9 (overweight), and > 30 (obese) 28 .

\section{- Media}

To evaluate the impact of the media on body change strategies we asked participants if they watched Iranian and western TV and whether they read fashion magazines or websites.

\section{Statistical analysis}

Descriptive statistics were used to summarize the data. The main outcome of the study (i.e. dissatisfaction score) was continuous. Therefore, the correlation between BMI and body dissatisfaction was assessed with Pearson's correlation. Two-way analysis of variance (ANOVA) was used to check the impact of age group and gender on body dissatisfaction. This is because these two independent variables were categorical. And lastly, linear regression analysis was performed to identify factors that influence body dissatisfaction in a multi-factorial setting. In the regression model, the associations of all independent variables with the outcome were considered simultaneously. All analyses were done using the SPSS software (SPSS Inc., Chicago, USA). A p-value $<0.05$ was considered to be significant. 


\section{Results}

The mean (SD) age was $31.06(10.24)$ with a minimum of 14 . Nearly two thirds of the participants were in the middle age group with moderate economic status. Furthermore, about half had a university education and were married (Table 1).

The mean \pm SD body dissatisfaction score for women and men was $1.08 \pm 0.94$ and $0.91 \pm 0.81$, respectively $(95 \%$ CI: 0.08; 0.28, p-value $=0.001)$ (Table 1$)$. The mean $(\mathrm{SD})$ body dissatisfaction scores for single and married participants were $0.85(0.89)$ and $1.11(0.87)$, respectively $(\mathrm{p}<0.0001)$. Additionally, the mean body dissatisfaction score was inversely associated with education (Table 1). The mean body dissatisfaction score was 1.2 in illiterate individuals or those with primary education only versus 0.89 in students or those with a university degree. However, the effect of media was not remarkable. These characteristics are shown in Table 1.

The proportion of women and men with normal or overweight BMI was roughly the same. However, the proportion of women classified as underweight and obese was remarkably higher than it was for men. The proportion of women and men classified as underweight was $73.5 \%$ versus $29.5 \%$. For the obese group, it was $65.3 \%$ and $34.7 \%$, respectively.

There was a positive correlation between BMI and body dissatisfaction $(r=0.37)$, which suggests an increase in BMI is associated with an increase in body dissatisfaction ( $<0.0001)$. The mean (SD) body dissatisfaction score for each BMI category was $0.72(0.76)$ in the normal group, $0.98(0.95)$ in the underweight group; 1.48 (0.72) in the overweight group; and $2.31(0.92)$ in the obese group. The body dissatisfaction score of about one third of participants (362 including 175 female and 186 male) was zero. This indicates that most of the participants (about two thirds) had some degree of body dissatisfaction. The results of two-way ANOVA revealed differences in the mean body dissatisfaction score based on age group and gender (Table 2). However, the pattern of body dissatisfaction varied for men and women. In participants less than 20 years old, the mean body dissatisfaction score of men was higher than women's (0.81 versus 0.73 ). For other age groups, however, the mean score for women was higher than for men (Table 2).

Lastly, we adjusted a multi factorial linear regression model to identify the variables that influence body dissatisfaction after adjusting it for other variables. Results are presented in Table 3. Age, gender, BMI, and education level were independently associated with body dissatisfaction, although marital status was of marginal significance. Women, older age groups and participants with higher BMIs were more dissatisfied with their bodies. The difference in the mean absolute dissatisfaction score between males and females was 0.10. In addition, the mean outcome in older age groups was about 0.25 higher than in younger age groups. The difference between obese and normal people, in terms of mean dissatisfaction, was as high as 1.54 . However, in relation to other groups, participants with a higher education level were more satisfied with their body shape.

\section{Discussion}

Body dissatisfaction, especially in relation to eating disorders, has attracted a lot of attention. Women are more prone to experiencing body dissatisfaction than men 6 . Researches have been conducted that suggest that the majority of women are dissatisfied with their body 6 . In this study, their body dissatisfaction had significant difference in relation to men's. It seems that in this Iranian population, like in other studies, women are in greater risk of body dissatisfaction than men 6,11,19.

In recent years, the number of researches focusing on body dissatisfaction in Asian cultures has increased. This research demonstrates that despite traditionally desirable body shapes, the Western ideal body type gained popularity 30 . Previous researches have indicated that compared to Western women, Asian women experience less body dissatisfaction, and a larger body size was considered attractive 30 . Other studies in other places have focused on this, finding rates of body dissatisfaction at $16 \%$ in Saudi Arabia 31,13\% in Palestine 32, and approximately 12\% in Pakistan 33. Although these researches focused on adolescents, it must be considered that body image dissatisfaction can continue in adulthood 34. For many years, body image satisfaction was considered a problem particular to adolescents and young people. Recent studies have shown that body image satisfaction there are through 


\section{Table 1}

Distribution of participants based on age, gender, marital status, education, body mass index (BMI) and use of media.

\begin{tabular}{|c|c|c|c|}
\hline Variable/Level & Frequency & $\%$ & Mean (SD) of body dissatisfaction \\
\hline \multicolumn{4}{|l|}{ Age (years) } \\
\hline$<20$ & 189 & 15.7 & $0.77(0.72)$ \\
\hline $20-40$ & 799 & 66.5 & $0.99(0.89)$ \\
\hline$>40$ & 214 & 17.8 & $1.25(0.94)$ \\
\hline \multicolumn{4}{|l|}{ Gender } \\
\hline Female & 635 & 54.3 & $1.08(0.94)$ \\
\hline Male & 549 & 45.7 & $0.91(0.81)$ \\
\hline \multicolumn{4}{|l|}{ Marital status } \\
\hline Single & 482 & 40.1 & $0.85(0.89)$ \\
\hline Married & 684 & 56.9 & $1.11(0.87)$ \\
\hline Widow/Divorced & 37 & 3.1 & $1.00(0.86)$ \\
\hline \multicolumn{4}{|l|}{ Education } \\
\hline Illiterate or primary & 168 & 14.0 & $1.20(0.93)$ \\
\hline High school & 395 & 32.9 & $1.10(0.88)$ \\
\hline University & 638 & 53.1 & $0.89(0.86)$ \\
\hline \multicolumn{4}{|l|}{ Economic status } \\
\hline Fair & 88 & 7.4 & $0.95(0.76)$ \\
\hline Moderate & 717 & 60.3 & $1.02(0.88)$ \\
\hline Good or excellent & 385 & 32.4 & $0.97(0.93)$ \\
\hline \multicolumn{4}{|l|}{ Use of TV } \\
\hline No & 15 & 1.3 & $0.67(0.72)$ \\
\hline Yes & 1,156 & 98.7 & $1.00(0.89)$ \\
\hline \multicolumn{4}{|l|}{ Use of satellite } \\
\hline No & 458 & 47.7 & $1.03(0.87)$ \\
\hline Yes & 502 & 52.3 & $0.95(0.93)$ \\
\hline \multicolumn{4}{|l|}{ Use of magazine } \\
\hline No & 288 & 27.3 & $1.04(0.83)$ \\
\hline Yes & 768 & 72.7 & $0.96(0.91)$ \\
\hline \multicolumn{4}{|l|}{ Use of Internet } \\
\hline No & 372 & 36.9 & $1.10(0.90)$ \\
\hline Yes & 635 & 63.1 & $0.93(0.90)$ \\
\hline \multicolumn{4}{|l|}{ BMI } \\
\hline Normal & 691 & 60.0 & $0.72(0.76)$ \\
\hline Thin & 149 & 12.9 & $0.98(0.95)$ \\
\hline Overweight & 263 & 22.8 & $1.48(0.72)$ \\
\hline Obese & 49 & 4.3 & $2.31(0.92)$ \\
\hline
\end{tabular}

SD: standard deviation.

Note: some of the values were not available for certain subjects. 
Table 2

Mean (SD) of body dissatisfaction regarding age groups and gender in one sample of Iranian general population.

\begin{tabular}{lccc}
\hline Age (years)/Gender & Mean & SD & $\mathbf{n}$ \\
\hline$<20$ & & & \\
Female & 0.73 & 0.67 & 96 \\
Male & 0.81 & 0.77 & 91 \\
Total & 0.77 & 0.72 & 187 \\
$20-40$ & & & 439 \\
Female & 1.07 & 0.94 & 344 \\
Male & 0.89 & 0.82 & 783 \\
Total & 0.99 & 0.89 & 105 \\
$>40$ & & & 108 \\
Female & 1.48 & 1.00 & 213 \\
Male & 1.03 & 0.81 & \\
Total & 1.25 & 0.94 &
\end{tabular}

SD: standard deviation.

Table 3

Predictive effects of marriage, body mass index (BMI) and education on body dissatisfaction in one sample of Iranian general population

\begin{tabular}{lccc}
\hline Variable/Level & B & SD & p-value \\
\hline $\begin{array}{l}\text { Marital status } \\
\text { Married }\end{array}$ & -0.03 & & \\
$\quad$ Divorced/Widowed & -0.32 & 0.06 & 0.62 \\
Gender & & 0.15 & 0.04 \\
$\quad$ Male & -0.10 & 0.05 & 0.03 \\
Age (years) & & & \\
20-40 & 0.23 & 0.07 & 0.002 \\
$\quad$ >0 & 0.25 & 0.10 & \\
BMI & & & $<0.0001$ \\
$\quad$ Thin & 0.28 & 0.07 & $<0.0001$ \\
$\quad$ Overweight & 0.72 & 0.06 & $<0.0001$ \\
$\quad$ Obese & 1.54 & 0.12 & \\
Education & & & 0.27 \\
High school & -0.09 & 0.08 & 0.02 \\
$\quad$ University degree & -0.18 & 0.08 & \\
\hline
\end{tabular}

SD: standard deviation.

life. Roy \& Payette 35 demonstrated that body dissatisfaction remains stable throughout life and has similarities and differences among young people. Depression, diminished quality of life and some health issues are the result of body dissatisfaction especially in middle-aged people 36 .

Although most researches regarding body satisfaction focused on adolescents and young adults, recent studies show that body dissatisfaction in the middle-aged group may be a problem that needs more attention.

In this study, we found that women who graduated from university had more body satisfaction than others. Researches about body image in relation to educational level are very few. In one study, 
Gavin et al. 37 showed that body satisfaction in females who graduated from college is greater than in other women. In recent years university education has increased dramatically in Iran. Many women in Iran are studying or have graduated from university. The number of female employees increased. Therefore these changes in socio-economic status can be considered contributing factors in body satisfaction for these women. This matter needs more researches and assessments for both genders and different social groups.

Another factor that contributed to body satisfaction is BMI. The BMI is highly correlated with body dissatisfaction for men and women 12 , especially adolescents and young adults. Increased body mass may be affect body dissatisfaction in two ways. These include one's body image devaluation (direct effect) and internalization of the advertised ideal body (indirect effect) 12. In our study, all categories of BMI had contributing effects on body satisfaction. Similarly, in previous studies with Iranian women, about $50 \%$ of women with normal weight were dissatisfied with their body image 38,39 . The relation between BMI and body dissatisfaction must be explored in future studies.

In our study there was a marginal difference between body dissatisfaction and marital status.

Studies have argued that family can be a source of pressure on individuals to achieve an ideal body. Findings regarding marriage and effects of having a spouse on body satisfaction are controversial.

Marriage can act both as a protective or risk factor in various health-related problems for women. Some research has found that there is no difference in body satisfaction between married and single women, but marital discord is correlated with body dissatisfaction ${ }^{37}$. Also, disapproval of appearance by one's partner is associated with greater body dissatisfaction among women 40 . In this study, we have not addressed various aspects of relations in marriage. Therefore, the role of marital and family structure needs further investigation.

The ideal body image concept is transmitted and even internalized by many sources, such as family, peers, and the mass media 12 . Many research demonstrates that exposure to messages from the media regarding ideal body types for men and women may result in body dissatisfaction and a variety of consequences such as low self-esteem, eating disorders, and maladaptive body change strategies 3,9,11. Some studies found a higher level of body dissatisfaction in boys exposed to athletic and attractive men in comparison to the control group.

Researchers have argued that Western media's influences on body image are located within a cultural context 8 . The examples of these cultural factors are seen in the differences between body dissatisfaction among Japanese and Taiwanese university students with similar exposure to Western influences 41 or Chinese adolescents. But it seems other factors also contribute to this effect. Asian media focuses on face or hairstyles slightly less than attractive and sexy bodies 9 .

In Iran, the use of women in advertisements is forbidden and male models are always fully dressed. Despite this, there are indirect media influences via TV or cinema stars (with the Western ideal body), or advertisements that promote body change strategies such as various kinds of diet, exercise equipment, drugs, and cosmetic surgery. Our finding that media does not affect body image is surprising. Body dissatisfaction may be due to a less direct influence of the Western ideal body type. Length of exposure to media can be effective in body dissatisfaction, though it is not considered in this study.

\section{Limitation}

This study was limited regarding body image and related issues in Iran. There are some strengths in this study including large sample size, sample selection in the general population and both genders and use of objective measurement tools rather than self-reports for body dissatisfaction assessment. But there are many limitations in this study. Qualitative studies may be more helpful than studies with cross-sectional design. In this study we do not assess the length and frequency of exposure to media and the type of media to which the subjects have been exposed. The assessment of socioeconomic status was self-reported. Another contributing factor is religion, as its role in west Asian cultures is important. In Iran, the majority of the population (more than 98\%) is Muslim, yet recent research has not considered the effect of religious attitudes, dressing and relations on body image. Religious attitudes, particularly those pertaining to Islam, should be considered in future researches. 


\section{Conclusions}

The findings of this study indicate that body image dissatisfaction is increasing in Iran. Body dissatisfaction is higher in women than men, but this issue must be taken seriously for men too. Although the pattern of body dissatisfaction in Iran is similar to that of Western cultures, there are many differences.

The comparison between similarity and differences in studies depends on the use of similar instruments and evaluation methods. In this study, we used body dissatisfaction as a whole, but in some of studies, body dissatisfaction was considered within a range. Therefore we cannot comment with certainty on the comparison with other studies.

Considering these results, we suggest that future researches should be conducted. Firstly, the role of other contributing factors such as the nature of media exposure, relationship with family and peers (encouragement or criticism), presence of psychiatric problems such as depression and religious attitude must be considered. Secondly, a follow-up study on the construction of a prediction model for body dissatisfaction and related issues, especially eating disorders, must be conducted.

\section{Contributors}

B. Garrusi developed the original idea and the protocol, wrote the manuscript, performed the critical review of the manuscript, was responsible for the study's supervision and is the guarantor. M. R. Baneshi contributed to the development of the protocol, in the acquisition of data, in the analysis and interpretation of data, in the statistical analysis, prepared the manuscript and reviewed it.

\section{Acknowledgments}

This research was conducted with the financial support of the Neuroscience Research Center, Institute of Neuropharmacology, Kerman University of Medical Sciences. We would like to thank all people that participated in this study for their cooperation. 


\section{References}

1. Williamson DA. Body image disturbance in eating disorders: form of cognitive bias. Eat Disord 1996; 4:47-58.

2. Grogan S. Body image: understanding body dissatisfaction in men, women, and children. 2nd Ed. New York: Routledge; 2007.

3. Grogan S. Body image development in adulthood. In: Cash TF, Smolak L, editors. Body image: a handbook of science, practice, and prevention. 2nd Ed. New York: The Guilford Press; 2011. p. 93-100.

4. Storvoll EE, Strandbu A, Wichstrom L. A cross-sectional study of changes in Norwegian adolescents' body image from 1992 to 2002 . Body Image 2005; 2:5-18.

5. McCreary D, Sasse DK. An exploration of the drive for muscularity in adolescent boys and girls. J Am Coll Health 2000; 48:297-304.

6. Kennedy MA, Templeton L, Gandhi A, Gorzalka BB. Asian body image satisfaction: ethnic and gender differences across Chinese, IndoAsian, and European-Descent students. Eat Disord 2004; 12:321-36.

7. Stice E. Review of the evidence for a socio-cultural model of bulimia nervosa and exploration of the mechanisms of action. Clin Psychol Rev 1994; 14:633-61.

8. Angelova RA, Utermohlen V. Culture-specific influences on body image and eating distress in a sample of urban Bulgarian women: the roles of faith and traditional fasting. Eat Behav 2013; 14:386-9.

9. Jackson T, Jiang C, Chen H. Associations between Chinese/Asian versus Western mass media influences and body image disturbances of young Chinese women. Body Image 2016; 17:175-83.

10. Pike KM, Borovoy A. The rise of eating disorders in Japan: issues of culture and limitations of the model of Westernization. Cult Med Psychiatry 2004; 28:493-531.

11. McCabe MP, Ricciardelli LA. A prospective study of extreme weight changes behaviors among adolescent boys and girls. J Youth Adolesc 2006; 35:425-34.

12. Jones DC, Crawford JK. Adolescent boys and body image: weight and muscularity concerns as dual pathways to body dissatisfaction. J Youth Adolesc 2005; 434:629-36.

13. Dittmar H. Vulnerability factors and processes linking sociocultural pressures and body dissatisfaction. J Soc Clin Psychol 2005; 24:1081-7.

14. Rukavina T, Pokrajac-Bulian A. Thin-ideal internalization, body dissatisfaction and symptoms of eating disorders in Croatian adolescent girls. Eat Weight Disord 2006; 11:31-7.

15. Owen PR, Laurel-Seller E. Weight and shape ideals: thin is dangerously. J Appl Soc Psychol 2000; 30:979-90.

16. Luo Y, Parish WL, Laumann EO. A population-based study of body image concerns among urban Chinese adults. Body Image $2005 ; 2: 333-45$.
17. Akiba D. Cultural variations in body esteem: how young adults in Iran and the United States view their own appearances. J Soc Psychol 1998; 138:539-40.

18. Nobakht M, Dezhkam M. An epidemiological study of eating disorders in Iran. Int J Eat Disord 2000; 28:265-71.

19. Garousi S, Garrusi B, Baneshi MR, Sharifi Z. Weight management behaviors in a sample of Iranian adolescent girls. Eat Weight Disord 2016; 21:435-44.

20. Rastmanesh R, Gluck ME, Shadman Z. Comparison of body dissatisfaction and cosmetic rhinoplasty with levels of veil practicing in Islamic women. Int J Eat Disord 2009; 42:339-45.

21. Stunkard AJ, Sorensen T, Schulsinger F. Use of the Danish adoption register for the study of obesity and thinness. Res Publ Assoc Res Nerv Ment Dis 1983; 60:115-20.

22. Fallon AE, Rozin P. Sex differences in perceptions of desirable body shape. J Abnor Psychol 1985; 94:102-5.

23. Thompson JK, Altabe MN. Psychometric qualities of the Figure Rating Test. Int J Eat Disord 1991; 10:615-9.

24. Gardner RM, Brown DL. Body image assessment: a review of figural drawing scales. Pers Individ Dif 2010; 48:107-11.

25. Markey CN, Markey PM, Birch LL. Understanding women's body satisfaction: the role of husbands. Sex Roles 2004; 51:209-16.

26. Runfola CD, Holle AV, Peat CM, Gagne DA, Brownley KA, Hofmeier SM, et al. Characteristics of women with body size satisfaction at midlife: results of the Gender and Body Image Study (GABI). J Women Aging 2013; 25:287-304

27. Zanjani Z, Goodarzi MA. Reliability and validity of Figure Rating Scale in Shiraz students. Mental Health Principles 2007; 10:149-55.

28. Centers for Disease Control and Prevention. Adult BMI. http://www.cdc.gov/healthyweight/assessing/bmi/adult_bmi/index.html (accessed on 10/Aug/2009).

29. Centers for Disease Control and Prevention. BMI for children and teens. http://www.cdc. gov/healthyweight/assessing/bmi/childrens_ bmi/about_childrens_bmi.html (accessed on 10/Aug/2009).

30. Malhotra S, Rogers E. Satellite television and the new Indian woman. Gazette 2000; 62:40730.

31. Al-Subaie AS. Some correlates of dieting behaviour in Saudi schoolgirls. Int J Eat Disord 2000; 28:242-6.

32. Latzer Y, Tzischinsky O, Asaiza F. Disordered eating related behaviours among Arab schoolgirls in Israel: an epidemiological study. Int J Eat Disord 2000; 40:263-70.

33. Mumford DB, Whitehouse AM, Choudry IY. Survey of eating disorders in English-medium schools in Lahore, Pakistan. Int J Eat Disord 1992; 11:173-84. 
34. McCabe MP, Ricciardelli LA. Body image dissatisfaction across the lifespan: a review of past literature. J Psychosom Res 2004; 56:675-85.

35. Roy M, Payette H. The body image construct among Western seniors: a systematic review of the literature. Arch Gerontol Geriatr 2012; 55:505-21.

36. Kim BH, Choi JE. The relation between body image and quality of life for the middle age. Womens Health 2002; 3:105-19.

37. Gavin AR, Simon GE, Ludman EJ. The association between obesity, depression, and educational attainment in women: the mediating role of body image dissatisfaction. J Psychosom Res 2010; 69:573-81.

38. Nikniaz Z, Mahdavi R, Amiri S, Ostadrahimi A, Nikniaz L. Factors associated with body image dissatisfaction and distortion among Iranian women. Eat Behav 2016; 22:5-9.
39. Heshmat R, Fakhrzadeh H, Pour-Ebrahim R, Nouri M, Alaeddini F. Cardiovascular risk factors study in the inhabitants of Tehran University of Medical Sciences population lab: statistical design and sampling. J Diabetes Metab Disord 2004; 3:21-6.

40. Friedman MA, Dixon AE, Brownell KD, Whisman MA, Wilfley DE. Marital status, marital satisfaction, and body image dissatisfaction. Int J Eat Disord 1999; 26:81-5.

41. Shih MY, Kubo C. Body shape preference and body satisfaction in Taiwanese college students. Psychiatry Res 2002; 111:215-28. 


\section{Resumo}

Apesar da importância da satisfação com o próprio corpo para a autoestima e o bem-estar, pouco tem sido publicado sobre auto-imagem e como afeta as pessoas no Irã. O objetivo do estudo é avaliar a dismorfofobia e fatores associados na população geral iraniana. A amostra nesse estudo transversal incluiu aproximadamente 1.200 participantes (homens e mulheres) em 2011. Foram registrados a dismorfofobia (baseada na Figure Rating Scale), características demográficas, nível socioeconômico, indice de massa corporal (IMC) e uso da mídia. Quase dois terços dos participantes foram classificados no grupo de meia idade, e cerca da metade tinha nível superior. Dois terços estavam satisfeitos com o próprio corpo. A média $d a$ dismorfofobia era mais alta em mulheres ( $p<$ 0,0001). Idade, gênero, estado civil e IMC mostraram relação significativa com a dismorfofobia. Os achados destacam a necessidade do enfrentamento da dismorfofobia e suas consequências no Irã. A prevalência da dismorfofobia é tão alta quanto em outros países asiáticos, mas é igualmente importante considerar as variações culturais dentro desses países.

Imagem Corporal; Autoimagem; Aparência Física

\section{Resumen}

A pesar de la importancia de la satisfacción con el propio cuerpo para la autoestima y el bienestar, poco ha sido publicado sobre la auto-imagen y como afecta a las personas en Irán. El objetivo del estudio es evaluar la dismorfofobia y sus factores asociados en la población general iraní. La muestra en ese estudio transversal incluyó aproximadamente 1.200 participantes (hombres y mujeres) en 2011. Se registró la dismorfofobia (basada en la Figure Rating Scale), características demográficas, nivel socioeconómico, índice de masa corporal (IMC) y uso de los medios de comunicación. Casi dos tercios de los participantes se clasificaron en el grupo de mediana edad, y cerca de la mitad tenía nivel superior. Dos tercios estaban satisfechos con el propio cuerpo. La media de la dismorfofobia era más alta en mujeres ( $p<0,0001)$. Edad, género, estado civil e IMC mostraron una relación significativa con a dismorfofobia. Los hallazgos destacan la necesidad del enfrentamiento de la dismorfofobia y sus consecuencias en Irán. La prevalencia de la dismorfofobia es tan alta como en otros países asiáticos, pero es igualmente importante considerar las variaciones culturales dentro de esos países.

Imagen Corporal; Autoimagen; Apariencia Física
Submitted on $15 / \mathrm{Feb} / 2016$

Final version resubmitted on $13 /$ Oct/2016

Approved on 28/Nov/2016 